\title{
ТРЕХМЕРНАЯ МОДЕЛЬ СТРУКТУРЫ ЭМОЦИОНАЛЬНЫХ СОСТОЯНИЙ, ОСНОВАННАЯ НА РУССКОЯЗЫЧНЫХ ДАННЫХ
}

\author{
Д.В. ЛЮСИН ${ }^{\mathrm{a}, \mathrm{b}}$ \\ ${ }^{a}$ Национальный исследовательский университет «Высшая школа экономики», 101000, Россия, \\ Москва, ул. Мясницкая, д. 20

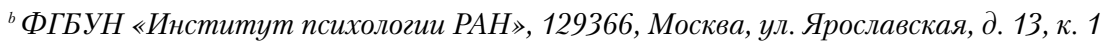

\begin{abstract}
Резюме
Предлагается модель, описывающая структуру эмоциональных состояний, в основу которой положены эмпирические данные, собранные на русскоязычных испытуемых. В зарубежной психологии чаще всего предлагаются двух- и трехфакторные модели, при этом получаемая структура зависит от языка, на котором собираются данные, и от культуры, к которой принадлежат испытуемые. Цель настоящего исследования состояла в том, чтобы выяснить, какие измерения лежат в основе самоописаний эмоциональных состояний на русском языке. Для сбора данных изначально был составлен максимально объемный список слов, используемых в русском языке для обозначения эмоциональных состояний. Этот список был сокращен до 56 слов, с помощью которых испытуемые (184 человека) оценивали свое эмоциональное состояние. Далее эксплораторный факторный анализ ответов позволил выявить главные измерения, лежащие в основе самоописаний эмоциональных состояний. Были получены три фактора: ЖОтрицательные эмоции с низкой активацией», «Положительные эмоции с высокой активацией» и «Напряжение». Выявленная структура обладает тремя особенностями. Во-первых, валентность эмоций оказалась не одним биполярным фактором, а распалась на отдельные ортогональные факторы положительных и отрицательных эмоций. Во-вторых, валентность эмоций оказалась до некоторой степени связанной с уровнем активации: положительные эмоции - с высоким, а отрицательные -c низким. В-третьих, в отдельный фактор выделились эмоциональные состояния, связанные с напряжением и неуверенностью. Можно предположить, что этот фактор выражает психическое напряжение в чистом виде, независимое от валентности. Предложенная модель структуры ядерного аффекта может быть положена в основу разработки методики для диагностики эмоциональных состояний.
\end{abstract}

Ключевые слова: эмоции, ядерный аффект, структура эмоциональных состояний.

Статья подготовлена в ходе проведения исследования по проекту № 16-01-0029 в рамках Программы «Научный фонд Национального исследовательского университета "Высшая школа экономики” (НИУ ВШЭ)» в 2016-2017 гг. и с использованием средств субсидии на государственную поддержку ведущих университетов Российской Федерации в целях повышения их конкурентоспособности среди ведущих мировых научно-образовательных центров, выделенной НИУ ВШЭ. 
Характерной чертой эмоциональных состояний является их исключительное разнообразие. Отсюда вытекает одна из традиционных проблем психологии эмоций, которая состоит в том, как наилучшим образом описывать и классифицировать разнообразные эмоциональные явления. Несмотря на большое количество идей и исследований, эта проблема остается не разрешенной. Настоящая работа направлена на то, чтобы предложить модель, описывающую структуру эмоциональных состояний, которая основана на эмпирических данных, собранных на русскоязычных испытуемых. Язык, на котором собираются данные, является важной особенностью таких моделей, потому что эмоциональный лексикон того или иного языка и принятые в нем способы описания эмоций могут влиять на получаемые результаты.

Термин «эмоциональные состояния» используется в настоящей работе для указания на широкий спектр эмоциональных явлений: от кратких эмоциональных реакций на конкретные события до настроений, которые могут длиться часами и сутками. Общий аспект этих явлений, важный в данном случае, - субъективное эмоциональное переживание, которое может быть осознано и подвергнуто вербальному описанию.

Существуют два основных подхода к описанию эмоциональных явлений, сложившиеся в современной психологии. Первый подход, категориальный, выделяет несколько эмоциональных категорий в качестве основных типов, а все остальные эмоциональные явления рассматривает как их особые варианты или смеси. Наиболее характерными представителями этого подхода являются, с одной стороны, теории базовых эмоций (например: Izard, 1977; Plutchik, 1984), с другой стороны, современные теории когнитивной оценки, описывающие «модальные», наиболее часто встречающиеся эмоции в качестве основных (Scherer, 1994).

Второй подход, который реализуется в настоящем исследовании, - многомерный. Он направлен на выявление нескольких основных параметров (измерений), которые можно использовать для описания всех эмоциональных явлений. Эти параметры задают n-мерное пространство, каждая эмоция в котором может быть представлена точкой, имеющей свои координаты по каждой из осей. Многомерный подход активно используется конструктивистскими теориями эмоций (Feldman Barrett, 2013), хотя для описания различий между эмоциями эти теории комбинируют оба подхода. Согласно их позиции, многомерный подход наиболее адекватен для описания «ядерного аффекта» (core affect), под которым понимается элементарное осознаваемое аффективное чувство, имеющее беспредметный характер и присутствующее в любом эмоциональном явлении. Ядерный аффект в наиболее чистом виде проявляется в настроении. Большинство многомерных моделей, описывающих эмоциональные состояния, предлагаются их авторами в качестве структурных моделей настроения или ядерного аффекта.

Важно отметить, что в русскоязычной литературе по психиатрии термин «ядерный аффект» используется, но под ним имеются в виду аффективные характеристики личности, предрасполагающие к развитию определенных расстройств (Вельтищев, 2006). Иногда этот термин проникает в психотера- 
певтическую литературу (Лызлов и др., 2011). В то время как в психиатрии ядерным аффектом называются некоторые устойчивые характеристики человека, в психологических теориях эмоций имеется в виду совсем другое центральная часть любого эмоционального явления, субъективно переживаемая как простое чувство, имеющее специфическую аффективную окраску.

В современной психологии эмоций существует несколько конкурирующих структурных моделей эмоциональных состояний. Дискуссия между ними ведется по двум основным вопросам: сколько измерений следует выделять (преобладают двухмерные и трехмерные модели) и каковы эти измерения.

Одной из наиболее известных современных двухмерных моделей является круговая модель Дж. Расселла (Russell, 1980; Feldman Barrett, Russell, 1999; Yik et al., 2011). В ней выделяются биполярные измерения валентности (положительные vs отрицательные эмоции) и активации (arousal). На эту модель очень похожа модель Р. Ларсена и Э. Динера (Larsen, Diener, 1992). Этим моделям противостоит двухмерная модель, предложенная Д. Уотсоном и A. Теллегеном (Watson, Tellegen, 1985), в которой выделяется две униполярные шкалы: позитивного аффекта (ПА) и негативного аффекта (НА). В каждой из этих шкал объединяются валентность и активация. Высоким баллам по шкале ПА соответствуют положительные эмоции с высокой активацией, а высоким баллам по шкале НА - отрицательные эмоции с высокой активацией. Особенностью модели Уотсона с соавт. является трактовка положительного и отрицательного аффекта не как двух взаимоисключающих полюсов одного измерения, а как двух ортогональных измерений. Это дает возможность описывать эмоциональные состояния смешанной валентности, т.е. переживаемые как положительные и отрицательные одновременно. Все упомянутые двухмерные модели имеют свой набор солидных эмпирических и теоретических аргументов, и дискуссия между ними остается актуальной.

Другой распространенный вид структурных моделей, описывающих эмоциональные состояния, - трехмерный. Самая ранняя модель такого рода была предложена В. Вундтом (Wundt, 1896), который на основе интроспективных данных выделял измерения «удовольствие - неудовольствие», «возбуждение - успокоение», «напряжение - разрядка». Очевидно, что первое измерение соответствует валентности, а два последних - активации в двухмерных моделях. Расщепление активации на два измерения, хотя бы относительно независимых друг от друга, получило поддержку в более поздних моделях. Например, Р. Тэйер выделяет измерения энергетического возбуждения (energetic arousal), противопоставляемого усталости, и возбуждениянапряжения (tense arousal), противопоставляемого спокойствию (Thayer, 1989). Показано, что эти два измерения различаются как на физиологическом, так и на психологическом уровне. Так, если студент успешно сдал важные экзамены и впереди его ожидают каникулы, то он может испытывать высокое энергетическое возбуждение при низком возбуждении-напряжении. Обратное сочетание - высокое возбуждение-напряжение при низком энергетическом возбуждении - может наблюдаться, например, у человека, ожидающего получить очень значимую негативную информацию, такую как 
терминальный диагноз. Два аспекта активации, выделенные Р. Тэйером, не только не зависят друг от друга, но и не связаны с валентностью (Schimmack, Reisenzein, 2002).

Одна из наиболее заметных трехмерных моделей последних лет предложена У. Шиммаком и А. Гробом (Schimmack, Grob, 2000). Авторы применили структурное моделирование к оценкам испытуемыми собственных эмоций и показали, что данные лучше всего описываются моделью, содержащей измерения «удовольствия - неудовольствия», «бодрости - утомления», «напряжения - расслабления». Обращает на себя внимание удивительное сходство этой модели с моделью Вундта, несмотря на более чем вековую разницу во времени их создания и использование совершенно разной методологии. Аналогичной модели придерживаются и Дж. Мэттьюс с соавт. (Matthews et al., 1990).

Приведенные выше модели описывают структуру ядерного аффекта, хотя не все эти авторы используют именно данный термин. Кроме этого, существует ряд многомерных моделей, которые описывают не ядерный аффект, а структуру настроений, других эмоциональных явлений и даже эмоциональных значений стимулов. Среди таких моделей наиболее влиятельной в свое время была модель А. Мехрабьяна, выделяющая измерения удовольствия, возбуждения и доминирования (Mehrabian, Russell, 1974; Mehrabian, 1996) для описания как эмоциональных состояний, так и эмоциональной окраски стимулов. Она основывалась на трех измерениях, полученных Ч. Осгудом при анализе аффективной окраски слов, - оценки, активности и силы (Osgood et al., 1957). Модель Мехрабьяна заслуживает упоминания еще и потому, что выделяемые ею параметры положены в основу широко известной базы данных с эмоциональными изображениями IAPS (Lang et al., 2005). Однако параметр доминирования в настоящее время используется редко, так как он обычно не воспроизводится у других авторов. Важным исключением является «Женевское колесо эмоций» - круговая модель К. Шерера, в основе которой лежат измерения удовольствия и контроля, а интенсивность/ возбуждение выражаются расстоянием от центральной нейтральной точки (Scherer, 2005).

Другая структурная модель настроений, выделяющая четыре параметра, была предложена В. Наулисом и Х. Наулис (Nowlis, Nowlis, 1956). Они изучали, как психоактивные вещества, например амфетамин и барбитураты, влияют на настроение в условиях социального взаимодействия. Настроение измерялось самоотчетом с помощью списка прилагательных. Было получено четыре измерения: (1) активация, (2) социальная ориентация, т.е. стремление к общению или его избегание, (3) контроль или его утрата и (4) оценка происходящего как приятного или неприятного. Первое и последнее измерения соответствуют круговой модели Дж. Расселла, третье - параметру доминирования модели А. Мехрабьяна. Второе измерение выделилось, возможно, в связи с особенностями процедуры, так как испытуемые находились в контексте социального взаимодействия. 
К. МакКонвилл и К. Купер разработали иерархическую модель структуры настроения (McConville, Cooper, 1992). Они провели иерархический факторный анализ 170 пунктов из опросников, измеряющих настроение, и получили пять первичных факторов - «депрессия», «враждебность», «усталость», «тревога» и «экстраверсия» - и один генеральный фактор «гедонистический фон», т.е. валентность.

Если попытаться обобщить обзор структурных моделей, предлагаемых в рамках многомерного подхода к описанию эмоций, то можно констатировать, что наиболее распространены двух- и трехмерные модели. При их построении чаще всего используются данные, основанные на анализе эмоциональных терминов естественного языка, чаще английского. Остается непонятным, в какой степени эти модели можно переносить на широкий спектр разнообразных культур и языков. Например, У. Шиммак и А. Гроб считают, что двухмерные модели больше характерны для американских исследований, в то время как трехмерные модели чаще получаются у европейских исследователей. Можно предположить, что структура описания эмоциональных состояний может зависеть от культурной и/или лингвистической специфики.

В какой степени зарубежные модели подходят для описания эмоций при работе с русскоязычными участниками исследований? В отечественной психологии предпринимались отдельные попытки получить структурные модели эмоциональных состояний. Так, в работе О.С. Архипкиной (Архипкина, 1981) 14 испытуемых проводили парные сравнения 20 названий эмоций по шестибалльной шкале. Многомерное шкалирование дало три оси, которые были названы «гедонистический тон», «готовность к действиям» (уверенность vs сомнение, растерянность), «активация или степень выраженности чувственного тона» (тревога, опасение vs рассеянность). Хотя предложенные автором интерпретации шкал вызывают некоторые сомнения, все же можно отметить определенное сходство с моделью В. Вундта: первая шкала является шкалой валентности, вторая похожа на шкалу возбуждения, третья - на шкалу напряжения.

Н.Н. Данилова в серии исследований построила субъективное семантическое пространство терминов, описывающих эмоциональные и неэмоциональные состояния. Испытуемые ранжировали субъективные различия пар терминов, обозначающих эти состояния. С помощью многомерного шкалирования было получено три измерения, названные «знак», «эмоциональная активация» и «неэмоциональная активация или готовность к действию» (Данилова и др., 1990). До некоторой степени их также можно отождествить с тремя шкалами в модели В. Вундта, идущими в последовательности «валентность», «напряжение», «возбуждение».

А.В. Вартанов с соавт. в серии публикаций предложил четырехмерную сферическую модель эмоций (Вартанов, Вартанова, 2003; Вартанов, 2013). Для получения данных для многомерного шкалирования испытуемым предъявлялось одно и то же слово (в одной серии «да», в другой серии «нет»), произносимое с 20 разными эмоциональными окрасками; в еще одной серии предъявлялось 22 названия эмоций. Испытуемые (25 человек) проводили 
парные сравнения стимулов. В результате были получены четыре оси, интерпретируемые автором как знак эмоции, информационная определенность, активноe vs пассивное отвержение и притяжение. Однако детальный анализ координат стимулов в системе полученных четырех осей свидетельствует о том, что интерпретация этих осей, кроме первой, достаточно сложна и неоднозначна.

В целом существующие отечественные работы анализируют довольно ограниченный спектр эмоций, а данные, лежащие в их основе, собраны на маленьких выборках испытуемых. В совокупности это не позволяет рассматривать их результаты как достаточно убедительные.

Цель настоящего исследования состояла в том, чтобы выяснить, какие измерения лежат в основе самоописаний эмоциональных состояний на русском языке, и предложить структурную модель эмоциональных состояний.

Для реализации этой цели использовалась следующая стратегия. На первом этапе был составлен максимально объемный список слов, используемых в русском языке для обозначения эмоциональных состояний. Потом он сокращался с помощью экспертов (лингвистов и психологов) за счет исключения очень близких по значению и многозначных слов. В результате был получен список из нескольких десятков слов, который позволял описывать максимально широкий спектр эмоциональных состояний на естественном языке. На втором этапе большая выборка респондентов с помощью этого списка оценивала свое эмоциональное состояние. Далее эксплораторный факторный анализ ответов позволил выявить главные измерения, лежащие в основе самоописаний эмоциональных состояний.

\section{Этап 1. Составление списка названий эмоций для описания респондентами своих эмоциональных состояний}

Задача этого этапа заключалась в том, чтобы составить список слов, который достаточно полно описывал бы разнообразие эмоциональных состояний человека. Вместе с тем этот список должен был быть не слишком большим, чтобы не вызвать чрезмерного утомления, и не должен был содержать слов, непонятных участникам исследования. Слова в списке должны были позволять испытуемым достаточно легко и однозначно соотносить их со своим эмоциональным состоянием.

Для составления исходного списка использовались словари русского языка (Ляшевская, Шаров, 2009; Ожегов, Шведова, 2003) и неформальный опрос носителей русского языка. Было отобрано 330 имен существительных, в той или иной степени подходящих для описания эмоциональных состояний. Из этого набора были удалены явные синонимы и слова со слишком выраженной стилистической окраской. Таким образом был получен новый вариант списка, включавший 209 слов. Для его дальнейшего сокращения использовался метод экспертных оценок. В качестве экспертов выступили 14 человек (8 женщин, 6 мужчин). Десять из них имели филологическое образование и работали по специальности (преподаватель русского языка, журналист, 
редактор в издательстве и т.д.). Четыре эксперта имели высшее образование, но не в области филологии. Экспертам давали список слов, расположенных в алфавитном порядке, и просили оценить по пятибалльной шкале, насколько каждое слово подходит для описания эмоционального состояния, где 1 совсем не подходит и 5 - подходит полностью.

Согласованность полученных ответов оценивалась с помощью $\alpha$ Кронбаха, которая оказалась равна 0.865, что свидетельствует о высокой надежности результатов. Для дальнейшего исключения слов из списка использовались следующие критерии:

- слова оценивались экспертами как малоподходящие для описания эмоциональных состояний (средняя оценка ниже 2.9);

- высокая вариативность оценок экспертов (межквартильный размах выше 2.5);

- сложность для понимания обычными носителями русского языка: специальные термины и низкочастотные слова с неопределенным значением;

- близкие синонимы.

Перечисленные критерии носили не вполне формальный характер, однако они соответствовали главной задаче - сделать список удобным для работы респондентов (по объему и по значению входящих в него слов) и в то же время достаточно разнообразным для описания разных видов эмоциональных состояний.

В результате был получен список из 56 слов, который приводится в приложении 1.

\section{Этап 2. Выявление структуры эмоциональных состояний}

\section{Метод}

Выборка. Во втором этапе исследования приняли участие 184 респондента в возрасте от 17 до 62 лет $(\mathrm{M}=26.9, \mathrm{SD}=9.9)$, из них 53\% женского пола. Все они проживали в г. Москве, являлись представителями разных специальностей, бо́льшая часть были студентами вузов. Участие было добровольным.

Процедура. Респондентам предъявлялся список из 56 слов, полученный на первом этапе исследования. Слова были расположены в алфавитном порядке, напротив каждого слова приводились цифры от 1 до 5. Давалась следующая инструкция. «Перед Вами слова, которые описывают различные эмоциональные состояния. Пожалуйста, прочитайте внимательно каждое слово и отметьте, насколько оно соответствует Вашему эмоциональному состоянию в данный момент по пятибалльной шкале: 1 - совсем не подходит, 2 - подходит в малой степени, 3 - в среднем подходит, 4 - подходит в большой степени, 5 - подходит полностью». Бланки заполнялись индивидуально или в небольших группах. Участников просили выполнить задание в то время, когда они занимались повседневной активностью, например, большинство студентов заполняли бланки в перерывах между занятиями. Таким образом, можно сказать, что респонденты находились в условно-нейтральном состоянии. Это 
означает, что они находились в привычной для них обстановке, занимались привычными делами, и нет оснований предполагать, что в момент сбора данных они подвергались каким-либо особым эмоциональным воздействиям.

\section{Результатьь}

Собранные данные были подвергнуты эксплораторному факторному анализу по методу главных компонент. Задача состояла в том, чтобы выявить набор измерений, оптимальным образом описывающих эмоциональные состояния.

Перед началом обработки список из 56 слов был сокращен. У многих испытуемых возникали трудности при работе со словом желание, потому что они считали его не подходящим для описания эмоционального состояния. Слово облегчение у ряда испытуемых вызывало физиологические ассоциации, что мешало им следовать инструкции. Кроме этого, после сбора данных выяснилось, что некоторые слова подходили очень небольшому количеству испытуемых для описания своего состояния. Как правило, это были слова, обозначающие интенсивные эмоции, редко переживаемые в повседневной обстановке. Большинство испытуемых давали на эти слова ответ «1» и почти никто не давал ответы «4» и «5». В результате были получены распределения ответов с выраженной положительной асимметрией. Было принято решение удалить такие слова из обработки, потому что они оказались в данном случае неинформативны и мешали проведению факторного анализа. В качестве критерия для удаления было выбрано количество ответов «1», оно должно было превышать 75\% от всех ответов на данное слово. В приложении 2 приводится список исключенных слов.

Окончательный список слов, ответы на которые были подвергнуты факторному анализу, включал 41 название эмоциональных состояний. Показатель КМО оказался равен 0.844, значимость теста сферичности Бартлетта $p<0.001$. Таким образом, полученную корреляционную матрицу можно считать пригодной для факторизации. Для определения количества факторов, которые будут подвергнуты вращению, использовался критерий Кеттелла. На графике собственных значений (рисунок 1) хорошо видна точка перелома на четвертой компоненте, на основании чего было выбрано трехфакторное решение. Проводилось ортогональное вращение факторов по методу варимакс с нормализацией по Кайзеру. В приложении 3 представлены факторные нагрузки. Интерпретация факторов проводилась по переменным с наиболее высокими факторными нагрузками ( $\geqslant 0.6$ по модулю для первых двух факторов и $\geqslant 0.5$ для третьего фактора), которые выделены жирным шрифтом. 
График собственных значений

Рисунок 1

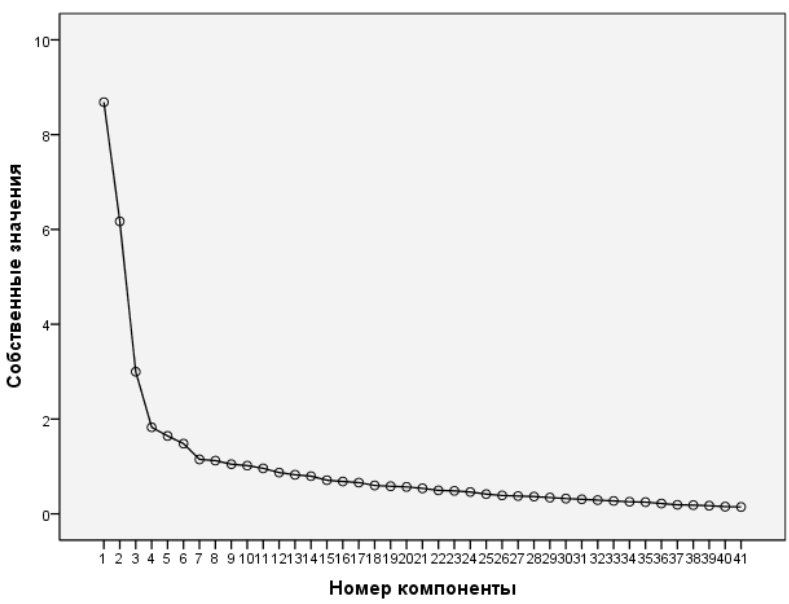

Наиболее высокие нагрузки по первому фактору получили переменные подавленность, опустошенность, грусть, огорчение, неудовольствие, досада, сожаление, по второму фактору - радость, воодушевление, удовольствие, торжество, восхищение, веселье, предвкушение, нежность, интерес, по третьему фактору - волнение, напряжение, беспокойство, тревога, озабоченность, сомнение, неуверенность и спокойствие (последняя с обратным знаком). Три фактора в совокупности объясняли 44\% дисперсии (после вращения первый $17 \%$, второй $-15 \%$, третий $-12 \%$ ).

Первый фактор может быть наилучшим образом проинтерпретирован как фактор отрицательных эмоций, при этом можно заметить, что бо́льшая часть этих эмоций связана с низким уровнем активации. Второй фактор, очевидно, является фактором положительных эмоций, бо́льшая часть которых связана с высоким уровнем активации. Наконец, на одном полюсе третьего фактора объединяются эмоции, связанные с напряжением и неуверенностью, в то время как противоположный полюс представлен спокойствием.

Также было проведено косоугольное вращение первых трех факторов по методу облимин, психологическое содержание полученных факторов оказалось совершенно таким же, как и при ортогональном вращении.

\section{Обсуждение}

Результаты показывают, что эмоциональные состояния можно описать с помощью трехфакторной структуры. Первый фактор можно назвать «Отрицательные эмоции с низкой активацией», второй - «оложительные эмоции с высокой активацией», третий - «Напряжение». Обращают на себя внимание три особенности полученной структуры. Во-первых, валентность эмоций оказалась не одним биполярным фактором, а распалась на отдельные 
ортогональные факторы положительных и отрицательных эмоций. Это позволяет говорить о том, что положительные и отрицательные эмоции не просто являются противоположными состояниями, но и относительно независимы друг от друга. Такое их соотношение помогает лучше понять феномен смешанных эмоций, так как допускает, что можно одновременно испытывать разные по знаку эмоции, например радость, смешанную с грустью, или нежность, смешанную с сожалением.

Во-вторых, валентность эмоций оказалась до некоторой степени связанной с уровнем активации: положительные эмоции - с высоким, а отрицательные с низким.

В-третьих, в отдельный фактор выделились эмоциональные состояния, связанные с напряжением и неуверенностью. Некоторые из этих состояний имеют отрицательную окраску, однако другие нейтральны с точки зрения валентности, например спокойствие, неуверенность, сомнение. Можно предположить, что этот фактор выражает психическое напряжение в чистом виде, независимое от валентности. В принципе оно может сочетаться и с отрицательными, и с положительными эмоциями (например, азарт или радость, связанная с рискованным поведением), хотя в повседневной жизни чаще сочетается именно с отрицательными переживаниями.

Примечательно также, что три полученных фактора ассоциируются с тремя основными эмоциональными расстройствами - депрессивным, маниакальным и тревожным.

Интересно провести сопоставление полученной структуры с наиболее известными и влиятельными зарубежными структурными моделями, описанными во введении. Первые два фактора соответствуют модели Д. Уотсона и А. Теллегена, в которой валентность и активация также смешиваются в каждом из двух измерений, хотя шкала отрицательных эмоций у них связана с высокой, а не с низкой активацией. Вместе с тем результаты не соответствуют круговой модели Дж. Расселла, в которой различаются два измерения валентность и активация. Благодаря наличию третьего измерения «напряжение» полученная структура оказывается похожей на модель В. Вундта, а также на модель У. Шиммака и А. Гроба, которые тоже выделяют напряжение как отдельный третий фактор. Стоит отметить, что не было получено фактора, хотя бы в какой-то степени напоминающего доминирование, предлагавшегося в модели А. Мехрабьяна и Дж. Расселла. Про этот фактор уже говорилось во введении, что он не воспроизводится в современных исследованиях.

Полученная модель может использоваться при описании любых эмоциональных явлений, потому что, по сути, она описывает структуру ядерного аффекта - элементарного аффективного чувства, лежащего в основе любого эмоционального опыта. В связи с этим данная модель не предназначена для тонкой дифференциации эмоциональных состояний. В основе некоторых эмоций может лежать один и тот же ядерный аффект, при этом различаться они будут другими компонентами - когнитивной оценкой ситуации, потенциалом совладания, соотнесенностью с Эго и т.п. Так, эмоции типа страха и злости будут характеризоваться в данной модели, прежде всего, высокими 
значениями по третьему измерению «напряжение». Одна и та же ситуация, например нападение, может вызвать у человека страх или злость в зависимости от того, как он оценивает свои возможности успешно отразить нападение и победить в конфликте. Этот пример показывает, как различные оценки ситуации и себя могут привести к возникновению разных эмоций, при том что ядерный аффект у них будет одинаковым.

Предлагаемая трехфакторная модель основана на самоотчетах испытуемых, находящихся в повседневном жизненном контексте и в большинстве своем не испытывающих интенсивных эмоций. Это является ограничением исследования, потому что остается неизвестным, будет ли и как именно меняться полученная структура при интенсивных эмоциональных состояниях разного типа. Для выяснения этого вопроса требуются дальнейшие исследования.

Полученная факторная структура может быть положена в основу разработки методики для диагностики эмоциональных состояний. Возможность адекватно описывать и диагностировать ядерный аффект важна для исследования эмоций и эмоциональных расстройств. В работах последних лет показано, что статические и динамические характеристики ядерного аффекта оказываются предикторами или признаками психологического благополучия (Houben et al., 2015), уровня самооценки (Kuppens et al., 2007), динамики межличностного поведения (Timmermans et al., 2010), депрессии и других эмоциональных расстройств (Kuppens et al., 2007). Диагностическая методика, основанная на предложенной модели, позволит развивать эти направления исследований на русскоязычном материале.

\section{Благодарности}

Автор благодарит за помощь в подготовке экспериментального материала и в сборе данных А.Г. Синкевича.

\section{Литература}

Архипкина, О. С. (1981). Реконструкция субъективного семантического пространства, означивающего эмоциональные состояния. Вестник Московского университета. Серия 14. Психология, 2, 40-46.

Вартанов, А. В. (2013). Антропоморфный метод распознавания эмоций в звучащей речи. Национальный психологический журнал, 10(2), 69-79.

Вартанов, А. В., Вартанова, И. И. (2003). Что такое эмоции? 4-х мерная сферическая модель аспектов переживания, выражения, восприятия и обозначения эмоций. В кн. Е. Е. Кравцова, В. Ф. Спиридонов, Ю. Е. Кравченко (ред.), Культурно-исторический подход и проблемьь творчества. Материалы третьих чтений, посвященных памяти Л.С. Выготского. Москва, 17-20 ноября 2002 года (с. 13-29). М.: РГГУ.

Вельтищев, Д. Ю. (2006). Аффективная модель стрессовых расстройств: психическая травма, ядерный аффект и депрессивный спектр. Социальная и клиническая психология, 16(3), 104-109. 
Данилова, Н. Н., Онищенко, В., Сыромятников, С. Н. (1990). Трансформация семантического пространства терминов состояний под влиянием информационной нагрузки в условиях дефицита времени. Вестник Московского университета. Серия 14. Психология, 4, 29-40.

Лызлов, А. В., Серавина, О. Ф., Ковалевская, О. Б. (2011). Тревога как ядерный аффект: опыт структурно-психологического анализа. Вопросы психологии, 4, 66-77.

Ляшевская, О. Н., Шаров, С. А. (2009). Новый частотный словарь русской лексики. М.: Азбуковник.

Ожегов, С. И., Шведова, Н. Ю. (2003). Толковый словарь русского языка (4-е изд.). М.: ИТИ Технологии.

Ссылки на зарубежные источники см. в разделе References после англоязычного блока.

Приложение 1

\section{Слова, предъявлявшиеся испытуемым для оценки своего эмоционального состояния}

безразличие

беспокойство

бодрость

веселье

вина

влюбленность

возбуждение

возмущение

волнение

воодушевление

восхищение

гнев

грусть

досада

желание

зависть

злорадство

интерес

напряжение недоумение

нежность

неприязнь

нетерпение

неуверенность

неудовольствие

обида

облегчение

огорчение

озабоченность

опустошенность

отвращение

подавленность

предвкушение

презрение

радость

раздражение

раскаяние

растерянность

\author{
ревность \\ скука \\ смущение \\ сожаление \\ сомнение \\ сочувствие \\ спокойствие \\ страдание \\ страх \\ стыд \\ торжество \\ тоска \\ тревога \\ уверенность \\ удивление \\ удовольствие \\ уныние \\ ярость
}

Приложение 2

\section{Слова, исключенные из списка 56 слов перед факторным анализом}

$\begin{array}{ll}\text { вина } & \text { презрение } \\ \text { возмущение } & \text { ревность } \\ \text { гнев } & \text { страдание } \\ \text { желание } & \text { страх } \\ \text { зависть } & \text { стыд } \\ \text { злорадство } & \text { уныние } \\ \text { облегчение } & \text { ярость }\end{array}$


Приложение 3

Факторные нагрузки для трехфакторного решения после вращения по методу варимакс

\begin{tabular}{|l|c|c|c|l|r|r|r|}
\hline & \multicolumn{3}{|c|}{ Факторы } & & \multicolumn{3}{c|}{ Факторы } \\
\hline & 1 & 2 & 3 & & 1 & 2 & 3 \\
\hline безразличие & 0.430 & -0.042 & -0.154 & озабоченность & 0.249 & 0.029 & $\mathbf{0 . 5 2 2}$ \\
\hline беспокойство & 0.156 & -0.143 & $\mathbf{0 . 6 9 5}$ & опустошенность & $\mathbf{0 . 7 7 4}$ & -0.155 & 0.188 \\
\hline бодрость & -0.359 & 0.371 & 0.097 & подавленность & $\mathbf{0 . 7 8 3}$ & -0.133 & 0.206 \\
\hline веселье & -0.254 & $\mathbf{0 . 7 1 2}$ & -0.065 & предвкушение & -0.051 & $\mathbf{0 . 6 9 6}$ & 0.086 \\
\hline влюбленность & 0.042 & 0.533 & 0.143 & радость & -0.237 & $\mathbf{0 . 8 0 0}$ & -0.073 \\
\hline возбуждение & -0.169 & 0.389 & 0.470 & раздражение & 0.421 & -0.041 & 0.237 \\
\hline волнение & 0.055 & 0.115 & $\mathbf{0 . 7 8 1}$ & раскаяние & 0.338 & 0.390 & -0.070 \\
\hline воодушевление & -0.156 & $\mathbf{0 . 7 7 2}$ & -0.001 & растерянность & 0.522 & 0.074 & 0.477 \\
\hline восхищение & 0.003 & $\mathbf{0 . 7 1 8}$ & -0.010 & скука & 0.469 & 0.005 & -0.090 \\
\hline грусть & $\mathbf{0 . 7 4 5}$ & -0.076 & 0.110 & смущение & 0.225 & 0.302 & 0.343 \\
\hline досада & $\mathbf{0 . 6 2 4}$ & -0.226 & 0.275 & сожаление & $\mathbf{0 . 6 0 0}$ & 0.146 & 0.054 \\
\hline интерес & -0.156 & $\mathbf{0 . 6 2 9}$ & 0.174 & сомнение & 0.414 & 0.135 & $\mathbf{0 . 5 0 2}$ \\
\hline напряжение & 0.161 & 0.021 & $\mathbf{0 . 6 9 7}$ & сочувствие & 0.393 & 0.436 & -0.161 \\
\hline недоумение & 0.477 & -0.027 & 0.218 & спокойствие & 0.128 & 0.190 & $-\mathbf{0 . 5 8 5}$ \\
\hline нежность & 0.214 & $\mathbf{0 . 6 5 1}$ & 0.087 & торжество & -0.052 & $\mathbf{0 . 7 3 1}$ & -0.175 \\
\hline неприязнь & 0.479 & 0.004 & 0.192 & тоска & 0.577 & -0.002 & 0.087 \\
\hline нетерпение & 0.070 & 0.203 & 0.466 & тревога & 0.306 & 0.034 & $\mathbf{0 . 6 5 8}$ \\
\hline неуверенность & 0.452 & -0.048 & $\mathbf{0 . 5 0 0}$ & уверенность & -0.219 & 0.312 & -0.496 \\
\hline неудовольствие & $\mathbf{0 . 6 6 5}$ & -0.166 & 0.268 & удивление & 0.244 & 0.475 & 0.056 \\
\hline обида & 0.477 & 0.028 & 0.244 & удовольствие & -0.159 & $\mathbf{0 . 7 3 7}$ & -0.090 \\
\hline огорчение & $\mathbf{0 . 6 9 2}$ & -0.016 & 0.219 & & & & \\
\hline
\end{tabular}

Люсин Дмитрий Владимирович - ведущий научный сотрудник, Научно-учебная лаборатория когнитивных исследований, Национальный исследовательский университет «Высшая школа экономики»; старший научный сотрудник, лаборатория психологии и психфизиологии творчества, Институт психологии РАН, кандидат педагогических наук, доцент.

Сфера научных интересов: психология эмоций, переработка эмоциональной информации. Контакты: ooch@mail.ru 


\title{
A Three-Dimensional Model of the Affect Structure Based on the Russian Data
}

\author{
D. Lyusin ${ }^{\mathrm{a}, \mathrm{b}}$ \\ ${ }^{a}$ National Research University Higher School of Economics, 20 Myasnitskaya Str., Moscow, 101000, \\ Russian Federation \\ ${ }^{b}$ Institute of Psychology, Russian Academy of Sciences, 13 build. 1, Yaroslavskaya Str., Moscow, 129366, \\ Russian Federation
}

\begin{abstract}
The well-known modern dimensional models of affect include two or three dimensions. They are typically based on self-reports using English emotion terms. It remains unclear to what extent these models can be applied to different cultures and languages. The present study is aimed at finding the dimensions underlying the descriptions of emotional states in Russian language and suggests a structural model of affect based on these findings. At the first stage, a comprehensive list of Russian nouns denoting emotional states was compiled. It comprised 330 words and was reduced to a list of 56 words. At the second stage, participants rated their emotional states using this list. The exploratory factor analysis yielded three dimensions that underlay participants' descriptions of the emotional states - negative affect with low activation, positive affect with high activation, and tension. This structure has at least three notable features. First, valence is not a bipolar factor like in some other structural models of affect. Instead, it splits into two orthogonal factors. Second, valence is somewhat related to arousal, namely positive affect is associated with high arousal and negative affect with low arousal. Third, emotional states related to tension and uncertainty form a separate factor. This factor presumably reflects pure tension independent from any valence. This model can be used for developing Russianbased measures for assessment of mood.
\end{abstract}

Keywords: emotion, core affect, affect structure.

\section{References}

Arkhipkina, O. S. (1981). Rekonstruktsiya sub"ektivnogo semanticheskogo prostranstva, oznachivayushchego emotsional'nye sostoyaniya [Reconstruction of subjective semantic space designating emotional states]. Vestnik Moskovskogo Universiteta. Seriya 14. Psikhologiya, 2, 40-46. (in Russian)

Danilova, N. N., Onishchenko, V., \& Syromyatnikov, S. N. (1990). Transformatsiya semanticheskogo prostranstva terminov sostoyanii pod vliyaniem informatsionnoi nagruzki $\mathrm{v}$ usloviyakh defitsita vremeni [Transformation of semantic space of the terms of states under the influence of informational load in a compressed time frame]. Vestnik Moskozskogo Universiteta. Seriya 14. Psikhologiya, 4, 29-40. (in Russian)

Feldman Barrett, L. (2013). Psychological construction: The Darwinian approach to the science of emotion. Emotion Review, 5, 379-389.

Feldman Barrett, L., \& Russell, J. A. (1999). The structure of current affect: controversies and emerging consensus. Current Directions in Psychological Science, 8, 10-14. 
Houben, M., Van Den Noortgate, W., \& Kuppens, P. (2015). The relation between short-term emotion dynamics and psychological well-being: A meta-analysis. Psychological Bulletin, 141, 901-930.

Izard, C. A. (1977). Human emotions. New York: Plenum Press.

Kuppens, P., Van Mechelen, I., Nezlek, J. B., Dossche, D., \& Timmermans, T. (2007). Individual differences in core affect variability and their relationship to personality and psychological adjustment. Emotion, 7, 262-274.

Lang, P. J., Bradley, M. M., \& Cuthbert, B. N. (2005). International Affective Picture System (IAPS): Affective ratings of pictures and instruction manual. Gainesville, FL: University of Florida.

Larsen, R. J., \& Diener, E. (1992). Promises and problems with the circumplex model of emotion. In M. S. Clark (Ed.), Review of personality and social psychology: Emotion (Vol. 13, pp. 25-59). Newbury Park, CA: Sage.

Lyashevskaya, O. N., \& Sharov, S. A. (2009). Novyi chastotnyi slovar' russkoi leksiki [New frequency dictionary of Russian language]. Moscow: Azbukovnik. (in Russian)

Lyzlov, A. V., Seravina, O. F., \& Kovalevskaya, O. B. (2011). The anxiety as a nuclear affect: An experience of structural-psychological analysis. Voprosy Psikhologii, 4, 66-77. (in Russian)

Matthews, G., Jones, D. M., \& Chamberlain, A. G. (1990). Refining the measurement of mood: The UWIST Mood Adjective Checklist. British Journal of Psychology, 81, 17-42.

McConville, C., \& Cooper, C. (1992). The structure of mood. Personality and Individual Differences, 13, 909-919.

Mehrabian, A. (1996). Pleasure-arousal-dominance: A general framework for describing and measuring individual differences in temperament. Current Psychology, 14(4), 261-292.

Mehrabian, A., \& Russell, J. A. (1974). An approach to environmental psychology. Cambridge, MA: The MIT Press.

Nowlis, V., \& Nowlis, H. H. (1956). The description and analysis of mood. Annals of the New York Academy of Science, 65, 345-355.

Osgood, C. E., Suci, G. J., \& Tannenbaum, P. H. (1957). The measurement of meaning. Urbana, IL: University of Illinois Press.

Ozhegov, S. I., \& Shvedova, N. Yu. (2003). Tolkovyi slovar' russkogo yazyka [Explanatory dictionary of Russian language] (4th ed.). Moscow: ITI Tekhnologii. (in Russian)

Plutchik, R. (1984). Emotion: A general psychoevolutionary synthesis. In K.R. Scherer \& P. Ekman (Eds.), Approaches to emotion (pp. 197-219). Hillsdale, NJ: Lawrence Erlbaum Associates.

Russell, J. A. (1980). A circumplex model of affect. Journal of Personality and Social Psychology, 39, $1161-1178$.

Scherer, K. (1994). Toward a concept of "modal emotions". In P. Ekman \& R. J. Davidson (Eds.), The nature of emotion: Fundamental questions (pp. 25-31). New York: Oxford University Press.

Scherer, K. (2005). What are emotions? And how can they be measured? Social Science Information, 44, 693-727.

Schimmack, U., \& Grob, A. (2000). Dimensional models of core affect: A quantitative comparison by means of structural equation modeling. European Journal of Personality, 14, 325-345.

Schimmack, U., \& Reisenzein, R. (2002). Experiencing activation: Energetic arousal and tense arousal are not mixtures of valence and activation. Emotion, 2, 412-417.

Thayer, R. E. (1989). The biopsychology of mood. New York: Oxford University Press.

Timmermans, T., Van Mechelen, I., \& Kuppens, P. (2010). The relationship between individual differences in intraindividual variability in core affect and interpersonal behavior. European Journal of Personality, 24, 623-638. 
Vartanov, A. V. (2013). Anthropomorphic method of emotion recognition in sounding speech. National Psychological Journal, 10(2), 69-79. (in Russian)

Vartanov, A. V., \& Vartanova, I. I. (2003). Chto takoe emotsii? 4-kh mernaya sfericheskaya model' aspektov perezhivaniya, vyrazheniya, vospriyatiya i oboznacheniya emotsii [What are emotions? Four-dimensional spherical model of aspects of experiencing, expressing, perceiving and designating emotions]. In E. E. Kravtsova, V. F. Spiridonov, \& Yu. E. Kravchenko (Ed.), Kul'turno-istoricheskii podkhod i problemy tvorchestva. Materialy tret'ikh chtenii, posvyashchennykh pamyati L.S. Vygotskogo. Moskva, 17-20 noyabrya 2002 goda [Cultural-historical approach and issues of creativity. Proceedings of the third readings in memoriam of L. S. Vygotsky] (pp. 13-29). Moscow: RGGU. (in Russian)

Vel'tishchev, D. Yu. (2006). Affektivnaya model' stressovykh rasstroistv: psikhicheskaya travma, yadernyi affekt i depressivnyi spektr [Affective model of stress disorders: psychic trauma, core affect and depressive spectrum]. Sotsial'naya i Klinicheskaya Psikhologiya, 16(3), 104-109. (in Russian)

Watson, D., \& Tellegen, A. (1985). Toward a consensual structure of mood. Psychological Bulletin, 98, 219-235.

Wundt, W. (1896). Grundriss der Psychologie. Leipzig: Engelmann. (in German)

Yik, M., Russell, J. A., \& Steiger, J. H. (2011). A 12-point circumplex structure of core affect. Emotion, 11, 705-731.

Dmitry Lyusin - leading research fellow, Laboratory for Cognitive Research, National Research University Higher School of Economics; senior research fellow, Laboratory of Psychology and Psychophisiology of Creativity, Institute of Psychology, Russian Academy of Sciences, Ph.D.

Research area: psychology of emotion, emotional information processing.

Email: ooch@mail.ru 